\title{
Carnets
}

Revue électronique d'études françaises de l'APEF

Première Série - 1 Numéro Spécial | 2009

Cultures littéraires : nouvelles performances \& développement

\section{A Literatura no contexto do Terceiro Milénio ocidental - Dodó ou Fénix?}

\section{Ana Alexandra Seabra De Carvalho}

\author{
(2) OpenEdition \\ Journals \\ Edição electrónica \\ URL: http://journals.openedition.org/carnets/3632 \\ DOI: $10.4000 /$ carnets.3632 \\ ISSN: 1646-7698 \\ Editora \\ APEF
}

Edição impressa

Data de publição: 1 Junho 2009

Paginação: 115-127

\section{Refêrencia eletrónica}

Ana Alexandra Seabra De Carvalho, « A Literatura no contexto do Terceiro Milénio ocidental - Dodó ou Fénix?», Carnets [Online], Première Série - 1 Numéro Spécial | 2009, posto online no dia 16 junho 2018, consultado o 01 maio 2019. URL : http://journals.openedition.org/carnets/3632 ; DOI : 10.4000/ carnets.3632

Este documento foi criado de forma automática no dia 1 Maio 2019.

\section{(c) (i) (8)}

Carnets est mis à disposition selon les termes de la licence Creative Commons - Atribution - Pas d'utilisation commerciale 4.0 International. 


\title{
A Literatura no contexto do Terceiro Milénio ocidental - Dodó ou Fénix?
}

\author{
Ana Alexandra Seabra De Carvalho
}

\section{NOTA DO AUTOR}

Centro de Estudos Linguísticos e Literários da Universidade do Algarve (financiado pela FCT) - Linha de Investigação intitulada Estudos Literários e Comparados - Tarefa 1:

"Identidades e Diferenças Europeias e Extra- Europeias no Plano Literário e Cultural".

1 A temática proposta para este Fórum APEF 2008 - "Culturas literárias: novas performances e desenvolvimento" - sugeriu-me uma tentativa de reflexão acerca da ameaça de extinção e das hipóteses de sobrevivência da cultura literária, do seu lugar e do seu papel social no mundo ocidental neste dealbar do século XXI.

2 Antes de mais, convém precisar que o lugar donde parto é o da Literatura, enquanto disciplina académica, embora relativizado pelo da História da Leitura, disciplina igualmente académica, porém mais recente. E parto da constatação da actual anarquia, que já se vinha a fazer sentir desde as últimas décadas do século $\mathrm{XX}$, das práticas de leitura ocidentais, em geral, e das do texto literário, em particular, anarquia essa que já não é só aparente mas sim bem real e mais generalizada do que se poderia supor, proliferando mesmo ao nível da cultura letrada e académica. Este novo modo de ler anárquico e egocêntrico reflecte-se, naturalmente, ao nível da produção literária, uma vez que grande parte dos autores contemporâneos deseja corresponder ao espírito do tempo e ao gosto do público, como de resto sempre aconteceu - na perspectiva da história das práticas de leitura e no sentido mais abrangente do termo "literatura" -, excepto nos casos mais radicais de estéticas defensoras do valor da "Arte pela Arte" - como, por outro lado, nos ensina a história da literatura, agora no sentido restrito e oitocentista de "arte da criação de um objecto estético verbal". Uma outra constatação, decorrente, a meu ver, 
entre outras razões, da situação anteriormente referida, prende-se com o aparente desrespeito e/ou a reinvenção do(s) cânone(s) da tradição literária(s) ocidental quer como lista dos "grandes autores", quer como convenções estéticas reflectidas nos textos de natureza teórico-crítica dos tratados de Poética e Retórica, da Antiguidade aos nossos dias, independentemente da forma que apresentem. Tentarei, então, sintetizar aqui algumas das principais pistas orientadoras dessa reflexão.

O título da minha comunicação - A Literatura no contexto do Terceiro Milénio ocidental - Dodó ou Fénix? - pressupõe, desde logo, a existência, no mundo ocidental e pelo menos até aos nossos dias, de um objecto cultural que nos habituámos a designar como "LITERATURA", independentemente da forma como o definimos, embora esta posição não seja unânime. Mas, ao levantar, em seguida, a questão da sua ameaça de extinção e das suas hipóteses de sobrevivência, contém implícita a ideia de MORTE desse objecto, tantas vezes vaticinada, quer de modo irónico quer de modo apocalíptico, por alguns sectores da intelectualidade finimilenar. Neste sentido, julgo ser legítimo questionarmo-nos sobre se o futuro da LITERATURA se assemelhará mais ao triste fim do DODÓ - essa grande ave palmípede das ilhas Maurícias, incapaz de voar, que se extinguiu no século XVIII por não se ter adaptado às novas condições impostas pelo predador humano - ou se, uma vez mais, terá a capacidade de renascer das próprias cinzas tal como a mítica FÉNIX?

Dito por outras palavras e tomando, naturalmente, as duas aves referidas como simples metáforas: será mesmo possível afirmar, como muitos pretendem, que a cultura literária tradicional, nos moldes em que a conheceram os leitores dos séculos XIX e XX, está condenada a "desaparecer" por incapacidade de adaptação aos novos tempos, diluída no imenso mar da pragmática textualidade geral e dos super-poderes de Leitor? Ou, pelo contrário, será ela capaz de renascer, ainda que transformada, recriada e, eventualmente, rebaptizada?

Dir-me-ão, talvez: mas então já não é literatura, é outra coisa qualquer, a definir a partir de objectos como: texto, discurso, hibrido de texto e audiovisual, hipertexto, enfim, o que quer que seja. Pois sim, respondo. No entanto, como todos se recordarão, o termo literatura significa, no seu sentido restrito, "arte que consiste no uso estético da linguagem, na produção de obras literárias”, e cito propositadamente o Dicionário da Língua Portuguesa Contemporânea da Academia das Ciências de Lisboa (2001), pois os dicionários gerais são excelentes para percebermos como o senso comum de uma determinada comunidade linguística interpreta os conceitos.

6 Contudo, esta concepção da literatura, ou seja, como a conheceram os leitores ocidentais dos séculos XIX e XX, é muito recente, como lembra Aguiar e Silva:

[F]oi na segunda metade do século XVIII que, em virtude de profundas transformações semânticas, o lexema literatura adquiriu os significados fundamentais que ainda hoje apresenta: uma arte que utiliza como meio de expressão e comunicação a linguagem verbal, uma específica categoria da criação artística, um conjunto de textos resultantes desta actividade criadora, uma instituição de índole sociocultural. (Aguiar e Silva, 2002: 38-39)

7 Mas como pode ela ter sido "inventada" na segunda metade do século XVIII se, porém, a nossa enciclopédia (no sentido de Umberto Eco) nos diz que a Literatura se perde na noite dos Tempos, devendo seguramente ser tão antiga como a capacidade humana para falar? De facto, a citação seguinte vai ao encontro dessa dúvida: “Ao que parece, duas causas, e ambas naturais, geraram a poesia. 0 imitar é congénito no homem (e nisso difere dos outros viventes, pois, de todos, é ele o mais imitador e, por imitação, apreende as primeiras 
noções), e os homens se comprazem no imitado" (Aristóteles, 1992: 1448 b 106- 107). Quem fala aqui é, como todos devem ter reconhecido, a primeira autoridade de referência incontornável na história da Teoria da Literatura ocidental. Aristóteles refere-se às origens da poesia, que para ele significa, como sabemos, imitação das acções e caracteres humanos por meio da palavra fabricada, isto é, diferente e ritmada (em verso ou não). E considera a imitação como natural à condição humana e diferenciadora relativamente aos outros animais, pois é pela imitação que o ser humano começa a sua aprendizagem do mundo (e quanto a esse aspecto, as mais modernas pesquisas no âmbito do estudo do funcionamento do cérebro dos recém-nascidos não poderiam estar mais de acordo). Para além dessa constatação, surge ainda a de que o prazer experimentado face ao resultado, ao objecto fruto dessa imitação - o imitado - também é da ordem da "natureza humana". Temos, então, duas das funções da poesia: ensinar e deleitar, associação positiva, no entender do Estagirita que, deste modo, se coloca numa posição contrária à do seu mestre Platão.

8 Pois bem, se substituirmos o termo Poesia por, sucessivamente, Belas-Letras e Literatura, por um lado; por outro, os termos imitar, imitação, imitado por, respectivamente, representar/ficcionar, representação/ficção, representado/ficcionado e, last but not least, o

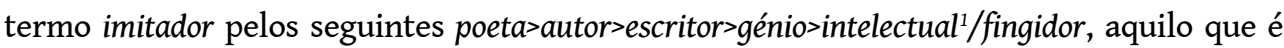
dito por Aristóteles quanto às origens da Poesia é, no contexto do seu tempo, equivalente ao que diríamos hoje ser a Literatura, pelo menos uma parte substancial dela - a ficção, no sentido anglo-saxónico de fiction ou da fiction genettiana ${ }^{2}$, tanto narrativa como dramática -, sentido esse que se foi constituindo ao longo da história cultural do Ocidente, como aqui referiu magistralmente Eduardo Lourenço na sua conferência de abertura.

9 Falta, é claro, a poesia, no seu sentido mais restrito, a lírica, para muitos, desde o romantismo alemão e Wordsworth, a verdadeira e única arte da linguagem, erigida, desde o século XVI, como o terceiro pilar da tríade dos modos literários: épico-dramático-lírico. É bem verdade que Aristóteles, no seu tratado, não se ocupa da poesia lírica - aquela em que o poeta fala exclusivamente em seu nome próprio e que corresponde à forma da poesia puramente narrativa, na classificação tripartida de Platão (sendo as outras duas formas a da poesia mimética do teatro, quando o poeta dá a voz exclusivamente às personagens, e a da poesia "mista" da epopeia, em que alternam as vozes do poeta e das personagens). E Aristóteles não se ocupa dela talvez por considerar que lhe faltam duas características, a seu ver, essenciais, da poesia: a da universalidade e a da mimese. Diz o filósofo: "o poeta deve ser mais fabulador que versificador; porque ele é poeta pela imitação e porque imita acções" (Aristóteles, 1991: 1451 b 116). Deste modo, a importância magna que a ficção assume nos nossos dias pode reclamar-se de inspiração aristotélica, tanto mais que tal fenómeno provém, sobretudo, do espaço da cultura anglófona, onde o Estagirita nunca deixou de estar presente enquanto teórico dos discursos retóricos e poéticos, isto é, literários.

10 Todavia, a importância do modo lírico na história da literatura ocidental é, desde os tempos anteriores a Aristóteles, por demais evidente para que o sistema literário não acabasse por vir a integrá-lo em termos teóricos, mas apenas muito depois de as práticas dos criadores e dos leitores já o haverem consagrado: basta pensarmos em Dante e Petrarca ou Rutebeuf e Villon, por exemplo.

11 Apesar disso, nos nossos dias, a ficção e, sobretudo, a narrativa - e o romance em particular - parecem representar a própria literatura, pelo menos ao nível da cultura mais massificada. Também neste caso o fenómeno nos vem do passado, primeiro com 
Pierre Huet, no século XVII, e a sua defesa da ficção baseada num forte argumento: se Jesus dela se serviu nas suas parábolas, ela só pode ser boa. No entanto, a valorização da ficção narrativa data mais concretamente da segunda metade do século XVIII, altura em que se verifica uma "fúria de ler" (Lesewut) criada tanto pela literatura de cordel como pelos best-sellers romanescos do tempo: Robinson Crusoe (1719) de Defoe, Pamela (1740-1) e Clarissa (1747-8) de Richardson, La Nouvelle Héloïse (1761) de Rousseau ou o Werther (1774) e o Wilhelm Meister (1796) de Goethe. Trata-se de exemplos de romances que não apenas foram aceites pelo cânone como acabaram por determinar várias linhas evolutivas do género.

12 No século seguinte, o romance - género tão desprezado pelos letrados setecentistas, que o consideram "leitura de mulheres", tão pueril quanto perigoso para a moral, os bons costumes e para as Belas-Letras (designação que, desde o século XVII, passa a rivalizar com a de Poesia) - triunfará no novo Panteão das Letras, de mãos dadas com a nova classe de poder, tornando-se assim na expressão literária da sociedade burguesa. E é esta associação poderosa que funda aquilo a que hoje poderíamos chamar o novo paradigma literário dos séculos XIX e XX, onde se criam novos grupos de leitores com interesses bem definidos: os operários e os públicos feminino e infanto-juvenil (Júlio Verne é um dos casos de maior sucesso editorial). Jornais e romances são os impressos mais consumidos, frequentemente até associados, como na fórmula de sucesso do romance- folhetim editado em suplemento ao jornal.

Embora possamos argumentar, com os seus contemporâneos parnasianos, que se trata, na maioria dos casos, de objectos esteticamente duvidosos, a verdade é que, do ponto de vista cultural, a sua importância é enorme, pois ela significa, em última análise, o acesso à leitura de uma massa anónima, cujos gostos não se confundem com o dos estetas. Mas também não podemos esquecer que o século XIX foi a Idade de Ouro do livro no Ocidente, ou seja, como notam Cavallo e Chartier ${ }^{3}$, a primeira geração a aceder à alfabetização em massa (dependendo, naturalmente dos países que consideremos) terá sido também a última em que o texto impresso não teve qualquer rival como meio de comunicação. Depois, como sabemos, entrarão em cena, no século $\mathrm{XX}$, o cinema, a rádio, a televisão, o texto electrónico e a Internet, provocando mais uma revolução nas práticas de leitura, logo, na concepção dos textos impressos e da Literatura.

Ora, justamente no final do Segundo Milénio, com o texto electrónico e as potencialidades quase infinitas do hipertexto, as condições de produção e recepção dos textos escritos, nomeadamente dos literários, alteram-se profundamente. Em síntese, e segundo os autores supracitados, podemos referir os seguintes aspectos:

- a possibilidade de simultaneidade entre criação/produção, transmissão e leitura de um mesmo texto;

- a reunião, num mesmo indivíduo, das tarefas até agora sempre distintas da escrita, edição e distribuição;

- a problematização dos direitos de autor, instituídos no final de Setecentos;

- a problematização das categorias estéticas que, desde o século XVIII,

- caracterizavam as obras: integridade, estabilidade, originalidade;

- a problematização das noções regulamentares: depósito legal, biblioteca nacional;

- a problematização das noções biblioteconómicas: catálogo, classificação, descrição bibliográfica.

Por outro lado, o objecto impresso não supõe a participação material, física daquele que o lê, e, deste modo, o leitor só pode insinuar a sua escrita nos espaços virgens do livro. 
Contudo, no texto electrónico tudo é diferente, como afirmam ainda Cavallo e Chartier ( op. cit.): o leitor pode submeter os textos a múltiplas operações (indexá-los, anotá-los, copiá-los, deslocá-los, recompô-los, etc.), mas mais ainda, ele pode tornar-se o seu coautor, ou seja, perante o ecrã, o leitor torna-se num dos actores duma escrita a várias mãos ou, pelo menos, encontra-se em posição de constituir um texto novo a partir de fragmentos livremente segmentados e reunidos. Tal como o proprietário de manuscritos, que podia reunir numa mesma antologia obras de natureza muito diversa, o leitor da idade electrónica pode construir, a seu bel-prazer, conjuntos textuais originais, cujas existência, organização e aparência só de si dependem. Mas ele pode ainda intervir a qualquer momento sobre os textos, modificá-los, reescrevê-los, torná-los seus, transformando profundamente a sua relação com os textos escritos, nomeadamente os literários, o que inquieta sobretudo os defensores da essencialidade da obra literária.

Também pela primeira vez na História, o texto electrónico autoriza a abolição da resignação do leitor voraz face à necessária parcialidade de qualquer biblioteca real quando confrontada com o sonho da Biblioteca total, contendo todas as obras escritas em todas as épocas e regiões da História da Humanidade, tão desejada quanto impossível, como Alexandria, Babel ou a Biblioteca imaginada por Borges. Seria então possível, se todos os textos estivessem digitalizados, a universal disponibilidade do património escrito na sala lá de casa.

Como bem sabemos, a leitura tradicional encontra-se, nos nossos dias, em forte concorrência com a imagem e o hipertexto e, simultaneamente, ameaçada de perder os repertórios, os códigos e os comportamentos que eram inculcados pelas normas escolares ou sociais. Para mais, como notam também os dois historiadores das práticas de leitura ocidentais já referidos, a transformação do suporte do texto escrito obriga o leitor a novos gestos e novas práticas intelectuais. Qual a consequência disso? Do códice ao ecrã o passo é tão gigantesco quanto o que ocorrera do rolo ao códice, pois com ele é a ordem dos livros, que fundou a identidade ocidental desde os primeiros séculos da era cristã, que é posta em questão. Novos modos de ler são, assim, afirmados ou impostos, de uma forma sem precedentes4. Em suma, ei-lo aí, o "admirável mundo novo" da era tecnológica, a do audiovisual e da hipermédia!

No contexto acima descrito, assalta-nos de novo a dúvida: haverá ainda esperança para a Literatura tal como a conhecemos? Para onde a levam esta nova desordem das práticas de leitura, a anarquia da produção criadora, o manifesto desrespeito - ou mesmo a recusa do chamado cânone ocidental, substituído por outros politicamente correctos (em alguns casos, porém, com toda a justeza)? Não estaremos, contudo, a esquecer que tal atitude não é original, já ocorreu noutros momentos da história do Ocidente e que acabou por constituir o principal motor da reinvenção contínua da Literatura enquanto sistema de códigos múltiplos e mutáveis, gerando movimentos e correntes diversos, numa tensão constante entre respeito pela tradição e audácia de experimentação? É que, tendo já passado por crises profundas no passado, a literatura sempre ressurgiu, metamorfoseada e transformadora da sociedade. Se a "coisa literária" surpreende pela sua capacidade de adaptação a novas realidades estéticas e culturais, pela sua auto-recriação, isso é porque nos estaremos a esquecer também de que tal plasticidade e eventual perenidade são a sua marca enquanto produto da invenção humana, tanto como jogos retórico-estilísticos, como jogos de espelhos da sociedade, da cultura e dos sistemas artísticos e científicotecnológicos. É claro que esses espelhos tanto podem ser mais "realistas" (como 
preconizava Stendhal, em Le Rouge et le Noir), como totalmente deformantes - idealizantes ou, pelo contrário, macabros e horrendos.

19 Na sequência da constatação anterior, se olharmos para o conjunto das principais Artes poéticas ocidentais, num contexto mais alargado que é abrangido pelas investigações da História do Livro e da Leitura, verificaremos que esses tratados sobre a Poesia, propondose como obras que analisam e/ou ensinam as regras para contar uma história (Aristóteles) ou para compor os poemas (Horácio), pelo menos até ao Romantismo, no fundo, reflectem os vários estádios da Literatura ao longo da sua história e traduzem frequentemente as posições e a estética de um grupo, ou fazem a síntese de uma estética mais abrangente, podendo ainda adoptar um registo polémico.

Assim, na nossa viagem no tempo, comecemos por recuar até à Antiguidade greco- latina, berço incontestável das questões que aqui nos interessam, a saber:

$211^{\text {o }}$ - a invenção, no século V a. C., da leitura silenciosa, embora usada em termos muito restritos apenas por estudiosos e poetas.

$222^{\mathrm{o}}$ - a importância determinante para toda a Literatura ocidental de dois textos de Aristóteles, a Poética e a Retórica, da Epístola aos Pisões de Horácio e ainda do anónimo Tratado do Sublime, o qual será traduzido para francês por Boileau e encantará a geração romântica...

$233^{\circ}$ - a importância simbólica da apropriação, por via da tradução-adaptação, da literatura grega feita por Roma (depois de se ter apropriado das suas importantes bibliotecas e colecções de livros particulares), a que se segue a difusão desta amálgama cultural por todo o espaço do Império romano, misturando-se ainda quer com a tradição judaica e o cristianismo nascente, quer com os mitos e lendas pagãos, nomeadamente os substratos culturais celta e nórdico, mas também o oriental.

$244^{2}$ - a importância, para o sucesso deste processo metamórfico, uma vez mais do contributo de Roma com a invenção do livro no formato do códice e a passagem definitiva, já nos primeiros séculos da era cristã, do rolo de papiro ao códice de pergaminho como suporte do texto escrito, e para a revolução das práticas de leitura que lhe estão associadas e que marcarão a cultura ocidental desde a época medieval até aos nossos dias. $5^{\circ}$ - a generalização, por volta do século X, no seio dos leitores monásticos de então, da leitura silenciosa, em que o texto, ao entrar pelos olhos, fala directamente ao espírito do leitor, como se uma voz estivesse dentro da sua cabeça. Do ponto de vista cultural e literário, trata-se de uma revolução da qual nós hoje mal nos conseguimos aperceber. $6^{\circ}$ - a apropriação literária, por via da tradução-adaptação em língua vulgar e de acordo com os novos valores da sociedade medieval, da herança cultural e literária greco- latina, sabiamente misturada com partes do imaginário sagrado da religião judaico-cristã e das culturas dos povos europeus e orientais. Durante este período, Horácio e a sua Epístola aos Pisões imperam em conjugação com a Retórica de Aristóteles, bem como com as autoridades da Eloquência latina - a dispositio e a elocutio são as partes mais valorizadas.

$7^{0}$ - a revalorização da cultura e literatura clássicas pelo Humanismo renascentista, associada à redescoberta e tradução da Poética de Aristóteles, a invenção da imprensa, a sistematização e a valorização das línguas vulgares como material poético de primeiraágua criam as condições propiciadoras à ocorrência de novas formas de metamorfose do literário. 

Classicismo francês), entre as designações de Poesia e Belas-Letras será um sinal de que os tempos estão, de novo, a mudar. De facto, a "Querela dos Antigos e Modernos", em França, lança, em contracorrente da Academia e de Boileau, a defesa do valor artístico dos autores modernos, nomeadamente da ficção, com Huet a fazer a apologia do género romanesco. Aliás, tanto em Espanha como em França, a ficção em prosa, repegando na tradição cortês e de cavalaria para a enaltecer ou parodiar, seja novela ou romance romanesco, tem uma grande aceitação por parte do público leitor.

$9^{\circ}$ - o sucesso a que podemos assistir, junto do público cada vez mais alargado do século XVIII, da valorização da prosa (tanto no romance, como no drama burgueses), assim como à oscilação entre a influência de Boileau e do racionalismo iluminista, por um lado, e, por outro, a partir de 1770, das novas ideias que vão chegando da Alemanha e de Inglaterra e que conduzirão à revolução romântica. O sucesso da ficção está associado à "fúria de ler" que parece ter contaminado as nações europeias na segunda metade de Setecentos. Tanto os romances da moda, que muitas vezes provêm da pena dos autores mais conceituados, como os textos de grande circulação a preços módicos, conhecidos como folhetos de cordel, são o alvo predilecto deste novo público voraz, o que a pouco e pouco vai diluindo as fronteiras entre a literatura erudita e a popular. Curiosamente ou não, este é o momento em que as aristocráticas Belas-Letras se começam a transformar numa mais democrática noção de Literatura, tal como hoje ainda a conhecemos. fazer sentir desde o século anterior estarão associados àquela revolução dos modos de ler. Como vimos, o século XIX será a Idade de Ouro do livro impresso e do jornal, sem rivais no que diz respeito à transmissão do saber, da informação, da cultura e da literatura. 0 público leitor alarga-se consideravelmente, manifestando os interesses próprios dos diversos grupos. Por seu turno, desde os alvores do século, a Literatura liberta-se das Belas-Letras (a partir da autonomização da História) e da Retórica, delimitando o seu campo, do qual ainda hoje somos herdeiros. Este nascimento de uma nova concepção do literário - e da disciplina académica correspondente - fica a dever-se à poética romântica, que procurou revolucionar a Poesia e as Belas-Letras clássicas, recuperando a herança medieval e shakespeariana, atribuindo valor estético tanto ao grotesco como ao sublime e recusando toda e qualquer normatividade imposta do exterior à própria obra, criação única de um génio inspirado. De agora em diante, instala-se uma tensão entre utilitarismo, como defesa dos géneros mais populares, encabeçados pelo romance romântico, realista ou naturalista, e estetismo, como defesa de uma concepção da "Arte pela Arte" do Parnasianismo e do Simbolismo, para quem "só é verdadeiramente Belo o que não serve para nada". Esta querela atravessará o século XX e perdura ainda nos nossos dias.

$31 \quad 11^{\circ}$ - No século XX, as diferentes correntes estéticas que se constituem em Escolas produzem "Manifestos" (ex.: o Surrealismo) com valor de Artes poéticas (pois estas haviam sido abolidas pelos românticos). As novas Artes poéticas vintistas, mesmo que não apresentem esta designação explícita, passam a abarcar o conjunto das formas e dos géneros - o romance, por exemplo -, procurando constituir-se como textos de natureza teórica, jogando com a intertextualidade no campo do debate sobre o fenómeno literário. A vanguarda vintista, nas suas diversas manifestações, é um "signo manifesto" da entrada da Cultura na era da Pós-Modernidade, a qual refuta uma concepção da Arte fundada no mito romântico da originalidade, no do progresso positivista e no da supremacia dos modelos ocidentais. 
Uma vez aqui chegados, convém questionarmo-nos se, à semelhança do passado, será ainda possível que (e como) as novas culturas literárias do presente e do futuro venham a conseguir preservar aspectos da tradição e a incorporar-lhe novas performances, fruto da invenção criativa em permanente transformação e da nova realidade tecnológica, prosseguindo o seu desenvolvimento de acordo com os novos tempos?

Como resposta, lancemos um olhar de relance sobre o modo de organização das propostas de comunicação deste Fórum. Aqui se sugerem alguns dos caminhos possíveis da investigação actual e futura no âmbito da Literatura e das suas relações com os outros domínios culturais, dos mais imbuídos de tradição aos mais ousados. Assim, por um lado, continua a investir-se em:

- criação literária e influências;

- culturas literárias e tradição popular;

- relação entre Literatura e Cultura/ gestão cultural;

- Literatura e Ensino;

- culturas literárias, identidade e intervenção;

-direitos do leitor, mas igualmente os seus deveres e limites.

Por outro lado, espelha-se uma zona mais caótica, no sentido positivo em que, a partir de uma situação de mal-estar, se pode chegar a uma mudança de paradigma (Khun):

- Literatura e média;

- escrita criativa e seus novos rumos na era digital;

- criação literária na era digital;

- perspectivas interculturais e pós-coloniais;

- correspondências interartísticas; etc.

Quer isto dizer que se constata, efectivamente, uma crise nos Estudos Literários na era da chamada Pós-Modernidade e do pragmatismo selvagem, em que proliferam as práticas de leitura anárquicas e egocêntricas (com muitos traços semelhantes aos da "leitura selvagem" do século XVIII). O novo leitor todo-poderoso decide usar os textos literários a seu bel-prazer ("eu cá só leio o que quero e como quero"), o que, por um lado, não tem mal nenhum quando estamos a ler para satisfação pura e simples do nosso prazer pessoal, enquanto sujeitos livres. Mas, por outro, já poderá ser muito pernicioso quando desempenhamos papeis social e culturalmente influentes, como os de crítico profissional e/ou professor de Literatura. Sendo verdade que os textos literários só existem em função de um leitor que os actualize e que esse leitor lê sempre no seu presente, também não é menos verdade que eles são igualmente objectos de natureza histórica, cultural e estética. Por conseguinte, arrastam consigo um lastro de leituras possíveis que emanam tanto deles próprios, enquanto estruturas linguísticas e retóricas entretecidas por uma multiplicidade complexa de códigos, como da história das leituras de que foram objecto por sucessivas gerações de comunidades interpretativas.

É certo, pois, que a cultura pós-moderna se instala como desconstrução dos valores da Modernidade e, no que à Literatura diz respeito, sobretudo como questionação do cânone, recusa do essencialismo estético - a famosa literariedade -, mas também a recusa da obrigatoriedade do novo (releia-se o poema Le Voyage de Baudelaire), originalidade esta que é diluída, por exemplo, através do pastiche, da colagem, da ironia desconstruidora dos códigos, nomeadamente ao nível da metaficção, etc.. Contudo, o pós-moderno ousou regressar aos poderes do sujeito, da Retórica, da historicidade e, portanto, da relatividade de todo e qualquer tipo de discurso, incluindo, claro está, o literário, domínio conquistado 
pelos poderes do Super-Leitor. Constatamos, assim, por um lado, a inter-relação do literário com a Cultura em geral - tanto a erudita quanto a popular e de massas na era do audiovisual e, mais recentemente, das TIC, onde a Internet surge como a grande novidade pelas potencialidades que tecnologicamente pode trazer à criatividade quer do autor, quer do seu mais do que nunca cooperante, ao ponto de se sobrepor ao primeiro, o todopoderoso Leitor. Mas constatamos, igualmente, a inter-relação do literário com os outros sistemas artísticos (de novo Baudelaire...), assim como com a Ciência e a Tecnologia (como também no Modernismo...), o que também só será novidade se virmos as suas formas actuais como muito diferentes das do passado. Se considerarmos a "hipermédia como síntese interactiva dos discursos" (como aqui propôs, ao longo destes trabalhos, Pedro Barbosa), perceberemos a fatalidade de o discurso literário aí vir a procurar novas vias de expansão, o que, num certo sentido, pode ajudar a acreditar numa (re)valorização da Literatura e dos Estudos Literários na era da Aldeia Global. Ou seja, e para concluir, é minha convicção que aquilo que, desde o século XIX romântico, designamos como Literatura, e cujas origens remontam tanto à cultura greco-latina da Antiguidade como à fundação religiosa judaico-cristã, como aqui lembrou Eduardo Lourenço, é uma arte semelhante à mítica Fénix, a qual, nos seus momentos de crise, sempre renasce das próprias cinzas, transformando-se eventualmente noutra coisa, reflexo da condição humana e da valorização da linguagem verbal em cada época da sua história no Ocidente, sendo simultaneamente um modo de criar as sociedades humanas. "Poesia", "Eloquência", "Belas-Letras", "Literatura", qual será a próxima designação? Não sei, mas terá a ver, acredito, com a homérica e aristotélica ficcionalidade da condição humana nas sociedades do futuro e com o encantamento do trabalho artístico da linguagem verbal, só ou acompanhada de outras linguagens.

\section{BIBLIOGRAFIA}

AGUIAR E SILVA, Vítor Manuel de (2002). Teoria e metodologia literárias. Lisboa: Universidade Aberta.

ARISTÓTELES (1992). Poética. Eudoro de Sousa (trad., introd. e notas). Lisboa: Imprensa Nacional Casa da Moeda.

CAVALLO, Guglielmo e CHARTIER, Roger (1997). "Introduction". In: Guglielmo Cavallo e Roger Chartier (dir.). Histoire de la lecture dans le monde occidental. Paris: Éditions du Seuil.

Dicionário da Língua Portuguesa Contemporânea da Academia das Ciências de Lisboa (2001). Lisboa: Editorial Verbo.

GENETTE, Gérard (1991). Fiction et Diction. Paris: Éditions du Seuil.

VIALA, Alain (2002). "Création littéraire”. In: Paul Aron et al. (dir.). Le Dictionnaire du Littéraire. Paris: PUF. 


\section{NOTAS}

1. Em ordem cronológica (Viala, 2002: 121-123).

2. Cf. Genette (1991).

3. Cf. Cavallo e Chartier (1997: 7-46).

4. Vide supra nota anterior.

\section{RESUMOS}

Propõe-se aqui uma reflexão sobre o lugar e papel social da cultura literária ocidental no Terceiro Milénio - continuaremos a falar de "Literatura" como nos séculos XIX e XX? Tanto a História da Literatura como a História da Leitura ocidentais mostram que o objecto literário é tão perene quanto plástico e adaptável a novas realidades estéticas e culturais. Então, não deveríamos, antes de decretarmos a extinção da Literatura, tentar perceber alguns dos caminhos para onde a poderão conduzir a nova desordem da leitura, a anarquia da produção criadora, o desrespeito pelo cânone ocidental tradicional e a invenção de novos cânones? Neste sentido, será ainda possível que (e como?) as novas culturas literárias venham a conseguir preservar aspectos da tradição e a incorporar-lhes novas performances, fruto da invenção criativa em permanente transformação e da nova realidade tecnológica, prosseguindo o seu desenvolvimento de acordo com os novos tempos?

This communication proposes to reflect about the place and the social role of western literary culture in the Third Millennium - will we continue to talk about "Literature", as in the nineteenth and twentieth centuries? Both History of Literature and History of Reading in the West show that the literary object is as enduring as plastic and adaptable to new aesthetic and cultural realities. Thus, shouldn't we, before decreeing Literature's extinction, try to understand some of the paths to where will lead it the new disorder of reading, the anarchy of creative production, the disrespect for traditional western canon and the invention of new canons? In this sense, would it still be possible that (and how?) new literary cultures come to preserve traditional aspects and be capable of incorporating new performances to them, as result of creative invention in permanent transformation and of new technological reality, and thus continuing its development in accordance with the new times?

\section{ÍNDICE}

Palavras-chave: Cultura literária ocidental, Século XXI, Dodó, Fénix

Keywords: Western Literary Culture, XXI Century, Dodo, Phoenix 
AUTOR

ANA ALEXANDRA SEABRA DE CARVALHO

FCHS e CELL, Universidade do Algarve

aacarva@ualg.pt 